\title{
CHRONIC PANCREATITIS IN CHILDHOOD
}

BY

\author{
THEODORE JAMES \\ From the Duchess of York Hospital for Babies, Manchester
}

(RECEIVED FOR PUBLICATION NOVEMBER 13, 1951)

Chronic pancreatitis in childhood is a disease which has very rarely appeared in the literature; indeed Davis and Kelsey (1951) in their recent review of the literature were able to find only three cases, to which they added one of their own, so making a total of four recorded cases.

When this condition is mentioned in paediatric textbooks it makes only the briefest appearance which gives little or no idea of the variations of symptomatology of which the illness is capable, nor of the magnitude of the diagnostic problem which may indeed be left unsolved. It is probably this latter difficulty which is the reason for so few case reports. The case reported is the youngest to be recorded.

\section{Case Report}

A.J.A. (No. 26154), a boy, aged 3 years, was admitted to the Duchess of York Hospital for Babies, Manchester, with the chief complaint of a swollen abdomen for at least two weeks. The mother was the informant, but she gave a strong impression that she was not a reliable witness and it was not unreasonable to believe that the onset of the illness dated back more than two weeks. She had noticed wasting of the patient 10 days before admission, the face, arms and chest becoming strikingly thin. The child had complained of abdominal pain, and he had vomited once nightly for three nights before admission. Also alternate loose and normal bowel evacuations were noted, but no blood in the stools. There had been no change in the patient's appetite which remained good up to the time of admission.

Pregnancy had been normal throughout and gestation brought to term. Labour and delivery were normal and neonatal progress uneventful. The birth weight was over $6 \mathrm{lb}$. $(2 \cdot 7 \mathrm{~kg}$.). The first teeth erupted at 8 months, at which age also the baby sat alone for the first time. At 16 months he was able to walk alone, and at 2 years was able to utter intelligible words. He had been immunized against diphtheria and pertussis, and the only illness contracted had been measles. There was no history of accident or abdominal trauma.

The father was well and 28 years old, the mother 27 years of age and well, although she did state that for many years since childhood she had 'been troubled with her chest' and there was some question about a haemoptysis at 14 years of age, but she had been radiographed five years previously, the lungs being reported clear. There were three siblings, a boy aged 5 years and well, a girl aged 4 years and well, and another boy aged 2 years and well. The mother had had one miscarriage, of unknown cause. No familial disease or trait was admitted.

Home conditions were very bad with strong evidence of neglect by the parents, but the other children of the family appeared well nourished. It is, perhaps, appropriate to mention here that throughout the patient's stay in hospital not once did either parent visit him, despite importuning on the part of the hospital staff, and it was only after the child had been recovered for some time that the mother could be persuaded to fetch him home.

Physical examination on admission showed a pale, wasted, chronically ill, red-haired boy. His temperature was $100 \cdot 2^{\circ} \mathrm{F}$. $\left(38^{\circ} \mathrm{C}\right.$.), pulse 146 , respiration 28 per minute. His weight was $23 \mathrm{lb} .9 \mathrm{oz}$. $(10.7 \mathrm{~kg}$.). The head circumference was 17 in. $(43 \mathrm{~cm}$.) and height 31 in. $(79 \mathrm{~cm}$.). In striking contrast to the wasted face, chest and extremities was a grossly distended abdomen, tense to palpation and dull to percussion, from which was also elicited a fluid thrill. No masses could be palpated, there was no noticeable tenderness, and no prominence of the superficial veins. There was a fair degree of pitting oedema about the sacrum and lower lumbar region and on the legs, ankles and dorsum of the feet, but nowhere else.

The other abnormal findings were a cardiac systolic murmur, most audible in the mitral region, and some diminished air entry into both lung bases. The immediate impression was that the patient was suffering from chronic tuberculous peritonitis.

A Mantoux test (1: 10,000 dilution of old tuberculin) was negative after 48 hours as were consequent $1: 1,000$, $1: 100$ and $1: 10$ dilutions. On the day after admission an abdominal paracentesis was carried out and $20 \mathrm{oz}$. $(560 \mathrm{ml}$.) of a light, reddish fluid removed. This ascitic fluid was obviously bloodstained and it contained, besides many red and white blood cells, some lumps of coagulum. There was little reduction of the distended abdomen following the paracentesis.

By the ninth hospital day the oedema over the lower back region was no longer present, but a mass suspected of being an enlarged spleen was palpated in the left hypochondrium, a fingerbreadth below the costal 
margin. The ascites increased and a second paracentesis was done on the eleventh hospital day, with the removal of about $11 \mathrm{oz}$. $(310 \mathrm{ml}$.) of a clear, straw-coloured fluid. The patient's general condition continued much the same as on admission.

An intravenous pyelogram showed a normal excretion of dye by both kidneys and no abnormality of the renal structures.

By the fifteenth hospital day, although there were signs of clinical improvement in the patient's general condition, the firm, smooth liver edge became palpable two fingerbreadths below the costal margin in the midclavicular line and this edge extended across the epigastrium and seemed to merge with the splenic mass. The abdomen by this time had become soft; without further paracenteses it no longer had any trace of ascites and all signs of the pitting oedema previously noted had disappeared. No therapeutic measures had been introduced.

By the nineteenth day the mass taken to be the spleen reached the level of the iliac crest, but three days later both this mass and the liver appeared to be receding. There was no associated lymphadenopathy and there was a progressive fall in the leucocyte count with a rise in the lymphocytes.

The child's general condition continued to improve, and on the twenty-fifth hospital day a tibial marrow puncture was done, but gave no lead to the diagnosis. Except for an intermittent spiking of the temperature the child appeared well, was of good colour, jolly and active by the twenty-ninth day. The abdomen was soft and small, but the receding splenic mass was still just detectable beneath the left costal margin. This mass and the liver edge were still palpable by the forty-first hospital day. On the forty-seventh hospital day the patient complained of some abdominal pain about the umbilicus where he was somewhat tender, and, although still lively, he spiked a febrile temperature and an indistinct mass was felt deep in the left hypochondrium and umbilical region. The spleen tip was only just palpable and the liver edge was one fingerbreadth down. The possibility of the deep mass being the pancreas was considered. A few days later, however, the abdomen was negative to examination and the child appeared very well in himself. He was active, playful, even mischievous about the ward. His body had filled normally and his general appearance was that of a chubby, healthy child. His weight during his stay in hospital changed from $23 \mathrm{lb} .9 \mathrm{oz}$. (10.7 kg.) on admission, to $22 \mathrm{lb} .15 \mathrm{oz}$. $(10.4 \mathrm{~kg}$.) by the twenty-fifth hospital day, to $26 \mathrm{lb} .12 \mathrm{oz}$. $(12 \cdot 1 \mathrm{~kg}$.) by the fifty-first, and on the day of discharge, 85 days after admission, it was $27 \mathrm{lb}$. (12.3 kg.), or $3 \mathrm{lb} .7 \mathrm{oz}$. $(2.5 \mathrm{~kg}$.) more than on admission.

Laboratory Data. On May 29, 1951, ascitic fluid was withdrawn. It was brownish-red, turbid, with a mass of coagulum, and alkaline to litmus, with a specific gravity of 1010 . Urea was $0.2 \mathrm{~g}$. \%. There was a deposit consisting of many pus cells and red blood cells. Protein was $3 \mathrm{~g}$. \%. No bacteria were seen on Gram staining.

On June 7 no malignant cells were detected on microscopy of the ascitic fluid, but a heavy deposit of leucocytes, lymphocytes predominating, was seen. The erythrocyte sedimentation rate was $3 \mathrm{~mm}$. in one hour. Haemoglobin was $70 \%$; erythrocytes $4.0 \mathrm{~m}$.; white blood cells 14,400 (polymorphs $70 \%$, lymphocytes $20 \%$, eosinophils $6 \%$, monocytes $4 \%$ ). On May 31 platelets were 480,000 per c.mm., and on July 26 haemoglobin was $76 \%$, erythrocytes $3.9 \mathrm{~m}$., white blood cells 8,500 (polymorphs $45 \%$, lymphocytes $48 \%$, eosinophils $6 \%$, basophils $1 \%$ ).

On May 29, 1951, blood urea was $25 \mathrm{mg} . \%$, and on May 30 examination of the urine gave an acid reaction, with a trace of protein, no sugar or acetone and nothing abnormal in the deposit. On July 10 the urine was normal.

Faeces were examined on June 28 and again on July 3 and 9 , but no salmonella or dysentery organisms were isolated.

Between June 7 and July 16 faeces, gastric washings and ascitic fluid were examined, but no tubercle bacilli were isolated.

On July 5 serum amylase was 800 units \% (normal values 90-163). On July 9 the urinary diastase index was 80 Wohlgemuth units (normal 6-30), on July 25 it was 5 W.u., and on July 2710 W.u. On August 14 serum amylase was 133 units $\%$ and the urinary diastase index 20 W.u.

A mumps neutralization test on August 16 was negative.

Wassermann and Kahn reactions were negative. Radiographs showed a benign bone cyst in the proximal metaphysis of the right humerus.

\section{Discussion}

In this case report of chronic pancreatitis in a boy of 3 years the diagnosis was reached by a process of exclusion, biochemical evidence of the disease still being present 54 days after the probable onset of the illness. Elman (1931) states that ' blood from patients with a normal pancreas has a normal blood amylase, whereas deviations from the normal are found only in cases of proved disease of the gland'. In the acute forms of pancreatitis the serum amylase level rises sharply within a few hours and falls to normal again in 24 to 48 hours (Wightman, 1948). In the chronic form without acute exacerbations and in the quiescent intervals of the chronic relapsing type the serum amylase is usually normal (Cantarow and Trumper, 1949). The serum amylase and lipase were elevated in the case of chronic relapsing pancreatitis in a boy of 8 years who was observed by Collett and Kennedy (1948) in an acute phase. The raised blood amylase in the case of Davis and Kelsey (1951) and in the present case is therefore of added interest. In the case of Davis and Kelsey the blood amylase determinations were made after the diagnosis had been established by operation and biopsy, and the amylase levels remained high for over 12 months, a most 
unexpected sequel. In the present case the high serum amylase, assayed by King's (1951) modification of Wohlgemuth's (1910) method, and the urinary diastase index fell to normal fairly quickly. An estimation of the amylase in the ascitic fluid would have been of great interest.

There is as yet no definitive clinical picture of chronic pancreatitis in childhood, but from the very few recorded cases in children it is suggested that the cases fall into two broad groups, chronic relapsing pancreatitis as discussed in a symposium by Gambill (1947), Baggenstoss (1947), and Comfort (1947) and chronic interstitial pancreatitis without the acute exacerbations which Opie (1910) described.

Abdominal pain is common. Collett and Kennedy's (1948) case, a boy of 8 years, had had recurrent attacks for four years. These had been severe on six occasions and five times had resulted in surgical exploration. Pains occurred in the two cases of Gambill (1947), and that of Davis and Kelsey, and in the present case they appear to have been very mild indeed. Opie in his account of chronic pancreatitis in adults lays no stress at all on abdominal pain.

Ascites has been less common, but was prominent in Davis and Kelsey's case and in my case, in which there was great abdominal distension. The appearance of the ascitic fluid in both cases was very similar. The first paracentesis in each case produced a reddish fluid which in my case had become amber 10 days later. In Davis and Kelsey's case repeated paracentesis produced a reddish fluid which became amber-coloured at operation nine days later. Vomiting was conspicuous in the others, but only slight in my case. Food precipitated the pain in one of the two cases of Comfort, Gambill and Baggenstoss (1946). Weight loss with wasting and oedema has not been uncommon, having been remarked upon in three of the five cases. Hepatomegaly was present in one of the cases of Comfort et al., and there was also splenomegaly in the case of Collett and Kennedy (1948) and in my case. Collett and Kennedy's case showed abnormal liver function tests.

The very striking enlargement of the spleen in the present case and its eventual complete recession is not easily explicable. A hypothesis is that the pancreas became swollen by whatever pathology was affecting the gland and that the swelling compressed and occluded the splenic vein, producing back pressure and passive congestion of the spleen which resolved pari passu with the recovery of the pancreas. Some weight is lent to this hypothesis by Opie (1910) who remarks upon the likelihood of the splenic vein becoming thrombosed in the acute haemorrhagic forms of pancreatic disease. By inference it is a possibility that thrombosis of the splenic vein was the cause of the splenomegaly whose resolution was brought about by re-canalization and/or the opening up of subsidiary channels. And Comfort et al. (1946) say 'splenomegaly (chronic passive congestion) may well be due to partial obstruction of the splenic vein '.

One of the cases of Comfort et al., complicated by diabetes mellitus, developed oedema of the face, legs and lower part of the back, and ascites. Davis and Kelsey's patient had minimal pitting oedema of the legs with ascites, and my case had marked pitting oedema of the lower extremities and the lower back associated with marked ascites.

The case of Collett and Kennedy (1948) was remarkable in that it was associated with hyperlipaemia. Xanthomatous lesions of the skin were present from 15 months to 2 years of age and then disappeared on a low-fat diet. This is the only case in childhood with this manifestation, although Thannhauser is quoted as citing cases of hyperlipaemia with secondary xanthomatosis associated with chronic pancreatitis in adults.

Comfort (1947) pointed out the frequency of deposits of calcium in the pancreas, which were shown by radiography in 13 of 29 adult cases, but such deposits have not been demonstrated in children. Polymorphonuclear leucocytosis of moderate degree with eosinophilia and a raised erythrocyte sedimentation rate may be present.

There is no clear understanding of the cause of the disease as it occurs in early childhood. In his series of adult cases Opie gives as aetiological factors obstruction to the outflow of the gland's secretion by the pancreatic ducts (in 10 of 30 cases, pancreatic calculus in the duct of Wirsung); biliary calculi in the adjacent terminal part of the bile duct; new growths; ascending infection from the duodenum; arteriosclerosis of the blood vessels of the gland; tuberculosis, syphilis or inordinate intake of alcohol. In one of the adult cases of Comfort et al. (1946) infestation by Giardia lamblia was considered as a possible aetiological factor but was finally discounted. On three of the occasions when the case of Collett and Kennedy was surgically explored what appeared to be a ruptured abscess of the pancreas was disclosed, and generalized peritonitis was also found on three occasions, the cause for this not being determined.

Case 17 of Comfort et al., a boy of 12 years, had pancreatic ducts blocked by calculi with impaction in the head of the pancreas. The cause in the case of Davis and Kelsey, despite operation and biopsy, remained obscure and none of Opie's factors can be accepted as contributory in the present case.

Davis and Kelsey's patient had had mumps two 
years before the onset of the pancreatitis, but no relationship to the pancreatitis could be established. No history of mumps was obtained in the present case and mumps virus antibodies were not present.

It is of interest that whereas, following operation, Davis and Kelsey treated their case with $\mathrm{x}$-rays because of a report of nine cases of acute pancreatitis so treated by Morton (1945), and case 17 of Comfort et al. was similarly treated without apparent immediate benefit, in the present instance my patient received no special treatment, and resolution of the pancreatic affection proved very gratifying, although possible recurrences cannot be ruled out.

\section{Summary}

A case of chronic pancreatitis in a boy of 3 years of age is presented.

To the writer's knowledge this is the fifth and youngest case of chronic pancreatitis in childhood to be described.
The diagnosis, symptomatology and aetiology are discussed.

The patient was admitted to the Duchess of York Hospital for Babies under the care of Dr. S. K. Guthrie. Miss Pauline Gorse, of the Department of Biochemistry, Booth Hall Hospital, carried out the biochemical analyses.

\section{REFERENCES}

Baggenstoss, A. H. (1947). Proc. Mayo Clin., 22, 542.

Cantarow, A. and Trumper, M. (1949). 'Clinical biochemistry,' 4th ed. Philadelphia.

Collett, R. W. and Kennedy, R. L. J. (1948). Proc. Mayo Clin. 23, 158 .

Comfort, M. W. (1947). Ibid., 22, 548.

-, Gambill, E. E. and Baggenstoss, A. H. (1946). Gastroenterology, 6, 239.

Davis, M. L. and Kelsey, W. M. (1951). Amer. J. Dis. Child.,

Elman, R. (1931). Arch. intern. Med., 48, 828.

Gambill, E. E. (1947). Proc. Mayo Clin., 22, 537.

King, E. J. (1951). 'Micro-analysis in Medical Biochemistry,' 2nd ed. London.

Morton, J. (1945). Surgery, 17, 475.

Opie, E. L. (1910). 'Disease of the Pancreas,' 2nd ed., pp. 22, 200 , 209. Philadelphia.

Wightman, K. J. R. (1948). Med. Clin. N. Amer., 32, 518

Wohlgemuth, J. (1910). Berl. klin. Wschr., 47, 92. 